Uludag Univ. J. Fac. Vet. Med.

33 (2014), 1,2: 1-6

\title{
Damızlık Broyler Rasyonlarında Bitkisel Kaynaklı (Solanum glaucophyllum) 1.25-dihidroksikolekalsiferol Kullanılması
}

\author{
Gülay DENIZ $\quad$ Sümer SONGUR ${ }^{2}$
}

Geliș Tarihi: 30.04.2014

Kabul Tarihi: 21.05.2014

\begin{abstract}
Özet: Bu araştırmanın amacı; damızlık broyler rasyonlarına bitkisel kaynaklı (Solanum glaucophyllum) 1.25dihidroksikolekalsiferol $\left(1.25(\mathrm{OH})_{2} \mathrm{D}_{3}\right)$ katılmasının; yumurta ağırlı̆̆ı, yumurta kabuk kalitesi ve çıkım sonuçları üzerindeki etkilerini belirlemekti. Araştırma; 49 haftalık yaşta 40000 damızlık broylerin (Ross 308) bakıldığı Hastavuk A.Ş.'ye ait damızlık kümesinde ve aynı işletmenin kuluçkahanesinde yürütüldü. Araş̧ırmada kullanılan rasyonlar yine Hastavuk A.Ş.'ye ait yem fabrikasında toz formda hazırlandı. Araştırma süresince kontrol grubundaki hayvanların beslenmesinde Damızlık Broyler Rasyonu 1 (49-53. haftalar arası) ve Damızlık Broyler Rasyonu 2 (54-59. haftalar arası) kullanıldı. Deneme grubundaki hayvanların rasyonlarına kontrol grubundan farklı olarak 10 ppm dozda Solanum glaucophyllum kaynaklı $1.25(\mathrm{OH})_{2} \mathrm{D}_{3}$ katıldı. $1.25(\mathrm{OH})_{2} \mathrm{D}_{3}$ katk1lı rasyonu tüketen deneme grubunun 59. haftada; yumurta kabuk kalınlığı $(\mathrm{P}<0.001)$, yumurta kabuk kırılma direnci $(\mathrm{P}<0.05)$ ve kırık yumurta oranında $(\mathrm{P}<0.05)$ istatistik düzeyde bir iyileşme saptandı. Ancak kontrol ve deneme grubunun yumurta ağırlıkları ve kuluçka sonuçları arasında önemli bir farklılık bulunmadı. Sonuç olarak; Solanum glaucophyllum kaynaklı $1.25(\mathrm{OH})_{2} \mathrm{D}_{3}$ 'ün ileri yaş dönemlerindeki damızlık broylerlerde yumurta kabuk kalitesini iyileştirebileceği ve kuluçka sonuçları üzerindeki etkisinin daha uzun süreli denemelerle ortaya konulabileceği kanısına varıldı.
\end{abstract}

Anahtar Kelimeler: Damızlık broyler, Solanum glaucophyllum, 1.25-dihidroksikolekalsiferol, kabuk kalitesi, kuluçka sonuçları.

\section{The Use of Herbal 1.25-dihydroxycholecalciferol (Solanum glaucophyllum) in Broiler Breeder Diets}

\begin{abstract}
The aim of this study was to determine effects of herbal (Solanum glaucophyllum) 1.25dihydroxycholecalciferol $\left(1.25(\mathrm{OH})_{2} \mathrm{D}_{3}\right)$ supplementation on the egg weight, eggshell quality and hatching results in broiler breeders. The experiment was performed at breeding hen house containing 40000 broiler breeders (49 weeks old) which belongs to Hastavuk A.Ş. The diets used in experiment also were prepared at the feed company of Hastavuk A.Ş. During experiment, broiler breeders in control group were fed with Broiler Breeder Diet 1(49-53 weeks) and Broiler Breeder Diet 2 (54-59 weeks). Broiler breeders in treatment group were fed diet containing $10 \mathrm{ppm}$ of herbal $1.25(\mathrm{OH})_{2} \mathrm{D}_{3}$ differently from control group. A significant improvement was determined at $59^{\text {th }}$ week in eggshell quality $(\mathrm{P}<0.001)$, eggshell breaking strength $(\mathrm{P}<0.05)$, cracked egg ratio $(\mathrm{P}<0.05)$ in treatment group supplemented with $1.25(\mathrm{OH})_{2} \mathrm{D}_{3}$. However, there was no significiant difference between control and treatment group in egg weight and hatching results. It was concluded that the supplementation of Solanum glaucophyllum sourced $1.25(\mathrm{OH})_{2} \mathrm{D}_{3}$ to the diets of aged broiler breeders may be effective eggshell quality and its effect can be demonstrated on the hatching results in long-term researh.
\end{abstract}

Key Words: Broiler Breeder, Solanum glaucophyllum, 1.25-dihydroxycholecalciferol, eggshell quality, hatcing results.

1 U.Ü. Veteriner Fakültesi, Hayvan Besleme ve Beslenme Hastalıkları Anabilim Dalı, Bursa, denizg@uludag.edu.tr

2 Hastavuk A.Ş., Görükle, Nilüfer, Bursa. 


\section{Giriș}

Vitamin D; kemik gelişimi, yumurta verimi, yumurta kabuk kalitesi ve üreme üzerindeki etkilerinden dolayı damızlık broylerlerin beslenmesinde önemli bir yere sahiptir. Damızlık broylerlerin vitamin D ihtiyaçları, rasyona rutin olarak ilave edilen vitamin premikslerindeki kolekalsiferol (Vitamin $\mathrm{D}_{3}$ ) yoluyla karş1lanır. Ancak vitamin $\mathrm{D}_{3}$ 'ün etkinliğini gösterebilmesi için; çeşitli enzimlerin etkisiyle önce tavuğun karaciğerinde 25-hidroksikolekalsiferol'e, daha sonra böbreklerinde 1.25dihidroksikolekalsiferol'e $\left(1.25(\mathrm{OH})_{2} \mathrm{D}_{3}\right)$ dönüşmesi gerekmektedir ${ }^{8}$. Vitamin $\mathrm{D}_{3}$ 'ün hidroksile olarak böbreklerde $1.25(\mathrm{OH})_{2} \mathrm{D}_{3}$ 'e dönüşmesiyle etkinliğinde 10 kat artış olduğu ileri sürülmektedir ${ }^{1}$. Vitamin $\mathrm{D}_{3}$ 'ün en aktif formu olarak kabul edilen $1.25(\mathrm{OH})_{2} \mathrm{D}_{3}$ 'ün vücutta $\mathrm{Ca}$ hemostasisinde önemli bir rol oynağı bildirilmektedir $^{7,14}$. Bilindiği gibi yumurta kabuğu, yumurtayı saran zarların üzerinde kalsiyum karbonat kristallerinin birikmesiyle oluşmaktadır. $1.25(\mathrm{OH})_{2} \mathrm{D}_{3}$ bağırsak epitelyumunda $\mathrm{Ca}$ bağlayıcı proteinlerin sentezini uyarmak suretiyle Ca'un bağırsaklardan emilimini ve uterusa transfer olmasını sağlayarak yumurta kabuğunun şekillenmesinde önemli bir rol oynamaktadir ${ }^{4}$. Yumurta kabuğu; embriyoyu diş etkilerden ve enfeksiyonlardan koruyarak, yumurtadan su kayıplarını önleyerek, ayrıca iskelet gelişimi için embriyoya gerekli Ca'u sağlayarak kuluçka sonuçlarını önemli düzeyde etkilemektedir ${ }^{11}$. Damızlık olarak yetiştirilen kanatlı hayvanların vitamin D ihtiyaçlarının yeterince karşılanmamas1, yumurta kabuk kalitesinin bozulmasına ve dolayısıyla kuluçka sonuçlarının olumsuz yönde etkilenmesine neden olmaktadir ${ }^{18}$. Ayrıca, embriyonun $\mathrm{Ca}$ metabolizmasında da önemli görevleri olan vitamin D düzeyinin damızlık yumurtalarda yetersiz olması geç dönem embriyo ölümlerine yol açarak kuluçka randımanını azaltmak$\operatorname{tadir}^{12,13}$.

Vitamin D'nin aktif formu olan $1.25(\mathrm{OH})_{2} \mathrm{D}_{3}{ }^{\prime}$ ün sentetik formunun kanatlı rasyonlarında kullanılması yüksek maliyetinden dolay1 pek tercih edilmemektedir. Solanum malacoxylon olarak da bilinen Solanum glaucophyllum adli bir bitki $1.25(\mathrm{OH})_{2} \mathrm{D}_{3}$ 'ün suda eriyen glikozitlerini doğal olarak içermektedir ${ }^{5}$. Fazla tüketilmesi durumunda toksik etkilere yol açan Solanum glaucophyllum'un hayvan besleme alanında kullanımı yönünde uzun yıllardır tavsiyeler yapılmıştır. Ancak, bu bitkiden $1.25(\mathrm{OH})_{2} \mathrm{D}_{3}$ içeriği standardize edilmiş bir ürün son yıllarda üretilebilmiștir. Dolayısıyla Solanum glaucophyllum kaynaklı $1.25(\mathrm{OH})_{2} \mathrm{D}_{3}$ 'ün kanatlı rasyonlarında kullanımına ilişkin çalışma sayısı oldukça yetersizdir.

$\mathrm{Bu}$ araştırma damızlık broyler rasyonlarına Solanum glaucophyllum kaynaklı $1.25(\mathrm{OH})_{2} \mathrm{D}_{3}$ katılmasının; yumurta ağırlığı, yumurta kabuk kalitesi (yumurta kabuk kalınl1ğ1, kabuk kırılma direnci, kırık yumurta oran1) ve çıkım sonuçları (dölsüz yumurta, çıkım, iskarta civciv ve embriyo ölüm oranları) üzerindeki etkilerini belirlemek amacıyla yapılmıştır.

\section{Materyal ve Metot}

$\mathrm{Bu}$ araştırma, Hastavuk A.Ş.'ye ait 49 haftalık yaşta 40000 damızlık broylerin (Ross 308) bakıldığ 1 damızlık broyler kümesi ile aynı şirketin kuluçkahanesinde yürütülmüştür. Damızlık kümesinin birbirinden bağımsız karşılıklı iki ayrı bölmeden oluşması; bölmelerden birinin kontrol, diğerinin ise deneme grubu olarak değerlendirilmesine olanak tanımıștır. Araștırma damızlık broylerler 49 haftalık yaşta iken başlatılmış ve 10 hafta sürdürülmüştür. Araştırma süresince kontrol ve deneme grubundaki hayvanların beslenmesinde $\% 18$ ham protein, 2750 $\mathrm{kcal} / \mathrm{kg}$ metabolik enerji içeren Damızlık Broyler Rasyonu 1 (49-53. haftalar arasi) ve \% 14.5 ham protein, $2750 \mathrm{kcal} / \mathrm{kg}$ metabolik enerji içeren Damızlık Broyler Rasyonu 2 (54-59. haftalar arası) kullanılmıştır. Deneme grubundaki hayvanların rasyonlarına kontrol grubundan farklı olarak 10 ppm dozda Solanum glaucophyllum kaynakl1 1.25(OH) ${ }_{2} \mathrm{D}_{3}$ (PAN-HVD; Herbonis AG, Basel, Switzerland) katılmıştır. Rasyonlar Hastavuk A.Ş.'ye ait yem fabrikasında toz formda hazırlanmıştır. Araştırmada kullanılan damızlık broyler rasyonlarının ham madde bileșimi ve besin madde içerikleri Tablo 1 'de gösterilmiştir.

Araştırma süresince; kontrol ve deneme grubundan elde edilen yumurtalardan kırıkçatlak olanlar günlük olarak kayıt altına alınmıştır. Yumurta kabuk kalitesinin belirlenmesi amacıyla; araştırmanın başlangıcı olan 49. hafta ile 51,53 , 55 ve 59 . haftalarda gruplardan tesadüfi örnekleme yöntemi ile 120'şer adet yumurta numunesi alınmıştır. Yumurta numuneleri; yumurta ağırlığı, yumurta kabuk kalınlığı ve yumurta kabuk kırılma direncinin belirlenmesi amaciyla Uludağ Üniversitesi Veteriner Fakültesi Hayvan Besleme ve Beslenme Hastalıkları Anabilim Dalı Laboratuvar'nna getirilerek oda sıcaklığında 24 saat süreyle depolanmıştır. Kontrol ve deneme grubunun yumurta ağırlıkla- 
r1, gruplara ait yumurtaları hassas terazide tek tek tartılıp ortalamalarının alınmasiyla belirlenmiştir. Yumurta kabuk kalınlığı, Egg Shell Thickness Gauge (ESTG-1, ORKA Food Technology Ltd., Ramat Hasharon, Israel) isimli bir cihaz kullanılarak ölçülmüştür. Her bir yumurtanın küt, sivri ve orta bölümünden olmak üzere toplam 3 ölçüm yapılmıș olup, bu ölçümlerin ortalamas1 alınarak grupların yumurta kabuk kalınlıkları saptanmıştır. Yumurta kabuk kırılma direnci ise kuvvet ölçme test cihazı (Imada ${ }^{\circledR}$, Newton) kullanılarak belirlenmiştir². Böylece araştırma süresince; kontrol ve deneme grubunun her birinden 600 yumurta olmak üzere, toplam 1200 adet yumurtada kabuk kalitesini belirlemeye yönelik ölçümler yapılmıştır.

Tablo 1. Araştırmada kullanılan damızlık broyler rasyonlarinın ham madde bileşimi ve besin madde içerikleri (doğal halde).

Table 1. Nutrient ingredients and chemical composition of the experimental broiler breeder diets (as fed basis).

\begin{tabular}{|c|c|c|}
\hline Ham Maddeler (\%) & $\begin{array}{c}\text { Damızlık Broyler } \\
\text { Yemi } 1 \text { (49-53. } \\
\text { Haftalar) }\end{array}$ & $\begin{array}{c}\text { Damızlık Broyler } \\
\text { Yemi } 2 \text { (54-59. } \\
\text { Haftalar) }\end{array}$ \\
\hline Misır & 44.01 & 50.34 \\
\hline Tam Yağlı Soya \%36 & - & 2.00 \\
\hline Soya Küspesi \%48 & 24.77 & 14.12 \\
\hline Buğday & 20.00 & 21.14 \\
\hline Ayçiçeği Küspesi \%28 & 1.86 & 2.95 \\
\hline Bitkisel Yağ & 0.50 & - \\
\hline Mermer Tozu & 6.53 & 7.70 \\
\hline MDCP \%22 & 1.14 & 0.72 \\
\hline Tuz & 0.26 & 0.23 \\
\hline Vitamin Premiksi ${ }^{1}$ & 0.25 & 0.25 \\
\hline Mineral Premiksi² & 0.10 & 0.10 \\
\hline Sodyumbikarbonat & 0.15 & 0.20 \\
\hline Kolin Klorid \%70 & 0.20 & 0.20 \\
\hline DL- Metiyonin & 0.23 & 0.05 \\
\hline TOPLAM & 100 & 100 \\
\hline \multicolumn{3}{|l|}{ Kimyasal Bileşim } \\
\hline Kuru madde, $\%$ & 87.89 & 87.88 \\
\hline Ham protein, $\%$ & 18.00 & 14.50 \\
\hline Ham yağ, \% & 2.68 & 2.72 \\
\hline Ham kül, \% & 9.19 & 9.95 \\
\hline Ham selüloz, \% & 3.21 & 3.49 \\
\hline Kalsiyum, \% & 2.8 & 3.20 \\
\hline Toplam fosfor, \% & 0.62 & 0.61 \\
\hline Lizin, \% & 0.89 & 0.66 \\
\hline Metiyonin+Sistin, \% & 0.68 & 0.60 \\
\hline Metabolik enerji, (kcal/kg) & 2750 & 2750 \\
\hline
\end{tabular}

${ }^{1}$ Yemin her kg'ına 15000 IU Vitamin A, 3500 IU Vitamin $\mathrm{D}_{3}, 100 \mathrm{mg}$ Vitamin E, $4.5 \mathrm{mg}$ Vitamin $\mathrm{K}_{3}, 3.5 \mathrm{mg}$ Vitamin $B_{1}, 18 \mathrm{mg}$ Vitamin $B_{2}, 8 \mathrm{mg}$ Vitamin $B_{6}, 0.04 \mathrm{mg}$ Vitamin $\mathrm{B}_{12}, 3 \mathrm{mg}$ Folik asit, $0.4 \mathrm{mg}$ D-Biotin, $60 \mathrm{mg}$ Nikotik asit, 20mg Pantotenik asit, 100 mg Vitamin C ilave edilmiştir.

${ }^{2}$ Yemin her kg'ına $80 \mathrm{mg}$ Manganez, $60 \mathrm{mg}$ Demir, $55 \mathrm{mg}$ Çinko, $12 \mathrm{mg}$ Bakır, $0.2 \mathrm{mg}$ Selenyum, $0.5 \mathrm{mg}$ İyot, 0.5 mg Kobalt, 200 mg Antioksidan ilave edilmiştir.
Araștırma süresince; kontrol ve deneme grubundan elde edilen kuluçkalık yumurtalar, Hastavuk A.Ş.'ye ait kuluçkahanenin rutin işleyiş düzenine uygun olarak 17 parti halinde kuluçkaya konulmuş ve her bir grup için 17 çıkım sonucu elde edilmiştir. Kontrol ve deneme grubundan elde edilen çıkım sonuçları yine Hastavuk A.Ş.'nin rutin kayıt sistemi gereğince kayıt altına alınmıştır. Bu araştırmada bitkisel kaynaklı $1.25(\mathrm{OH})_{2} \mathrm{D}_{3}$ ün damızlık broylerlerde kuluçka sonuçlarına etkisini belirlemek amacıyla grupların kayıt altına alınmış parametrelerinden; dölsüz yumurta, çıkım, 1skarta civciv ve embriyo ölüm oranları değerlendirmeye alınmıştır. Embriyo ölümleri; erken (0-6 gün), orta (7-17 gün) ve geç (18-21) dönem embriyo ölümleri olarak isimlendirilmiştir.

\section{İstatistik Analizler}

Grupların yumurta ağırlı̆̆ buk kalınlığı ve kabuk kırılma direncine ait verileri $\mathrm{T}$ Testi kullanılarak karşılaştırılmıştır. Kırık yumurta oranı ve kuluçka sonuçlarına ilişkin verilerin (dölsüz yumurta, çıkım, ıskarta civciv ve embriyo ölüm oranları) karşılaştırılmasında ise Ki-kare testi kullanılmıștır. Önemlilik düzeyi olarak $P<0.05$ seçilmiştir. İstatistik analizlerin yapılmasında SPSS 13 (SPSS 13. 2004) istatistik programından faydalanılmıştır ${ }^{16}$.

\section{Bulgular}

Araştırmada; kontrol ve deneme grubuna ait yumurta numunelerinin periyodik olarak değerlendirilmesi sonucu elde edilen yumurta ağılığı, yumurta kabuk kalınlığı, kabuk kırılma direnci ve kırık yumurta oranı değerleri Tablo 2 'de verilmiștir. Grupların kuluçka sonuçlarına ilişkin dölsüz yumurta, çıkım, 1skarta civciv ve embriyo ölüm oranları ise Tablo 3'te gösterilmiştir.

Tablo 2 incelendiğinde; araştırmanın başlangıcı olan 49. hafta ile araştırma süresince yapılan ölçümlerde $(51,53,55$ ve 59 . haftalar) kontrol ve deneme grubunun yumurta ağırlıkları arasında önemli bir farklılığın bulunmadığ anlaşılmaktadır. Aynı tablo incelendiğinde; $1.25(\mathrm{OH})_{2} \mathrm{D}_{3}$ katk1l1 rasyonu tüketen deneme grubunun 59. haftada kırık yumurta oranı $(\mathrm{P}<0.05)$, yumurta kabuk kalınlığı $(\mathrm{P}<0.001)$ ve yumurta kabuk kırılma direncinde $(\mathrm{P}<0.05)$ istatistik düzeyde bir iyileșmenin olduğu görülmektedir. Kuluçka sonuçlarına ilișkin değerlerin verildiği Tablo 3 incelendiğinde ise kontrol ve 
deneme grubunun dölsüz yumurta, çıkım, 1skarta civciv, erken, orta ve geç dönem embriyo ölüm oranları arasında oluşan farklılıkların istatistik açıdan önem taşımadığı dikkati çekmektedir.

Tablo 2. Bitkisel (Solanum glaucophyllum) kaynaklı 1.25(OH) $)_{2} \mathrm{D}_{3}$ 'ün yumurta ağırlığı, kırık yumurta oranı, yumurta kabuk kalınlığı ve kabuk kırılma direnci üzerine etkisi.

Table 2. Effect of herbal (Solanum glaucophyllum) 1.25( $\mathrm{OH})_{2} \mathrm{D}_{3}$ on egg weight, cracked egg ratio, eggshell thickness and eggshell breaking strength.

\begin{tabular}{|l|c|c|c|}
\hline & \multicolumn{2}{|c|}{ GRUPLAR } & \multirow{2}{*}{} \\
\cline { 2 - 3 } & $\begin{array}{c}\text { Kontrol } \\
\bar{X} \pm \mathrm{S} \bar{X}\end{array}$ & $\begin{array}{c}\text { Deneme } \\
\bar{X} \pm \mathrm{S} \bar{X}\end{array}$ & \\
\hline \multicolumn{3}{|c|}{ Yumurta Ağırlığı (g) } \\
\hline Başlangı̧ (49. Hafta) & $66.70 \pm 0.43$ & $67.46 \pm 0.40$ & ÖD \\
\hline 1. Ölçüm (51. Hafta) & $66.99 \pm 0.44$ & $67.50 \pm 0.46$ & ÖD \\
\hline 2. Ölçüm (53. Hafta) & $68.00 \pm 0.45$ & $69.33 \pm 0.45$ & ÖD \\
\hline 3. Ölçüm (55. Hafta) & $68.71 \pm 0.49$ & $68.49 \pm 0.45$ & ÖD \\
\hline 4. Ölçüm (59. Hafta) & $67.53 \pm 0.39$ & $66.46 \pm 0.40$ & ÖD \\
\hline Yumurta Kabuk Kırılma Direnci (N) \\
\hline Başlangıç (49. Hafta) & $36.54 \pm 0.41$ & $36.89 \pm 0.36$ & ÖD \\
\hline 1. Ölçüm (51. Hafta) & $36.73 \pm 0.43$ & $36.84 \pm 0.40$ & ÖD \\
\hline 2. Ölçüm (53. Hafta) & $36.60 \pm 0.39$ & $36.82 \pm 0.39$ & ÖD \\
\hline 3. Ölçüm (55. Hafta) & $36.31 \pm 0.37$ & $36.64 \pm 0.33$ & ÖD \\
\hline 4. Ölçüm (59. Hafta) & $36.19 \pm 0.45$ & $37.92 \pm 0.49$ & (P<0.05) \\
\hline Yumurta Kabuk Kalınlığı (mm) & \multicolumn{2}{|c}{} \\
\hline Başlangıç (49. Hafta) & $0.40 \pm 0.01$ & $0.39 \pm 0.01$ & ÖD \\
\hline 1. Ölçüm (51. Hafta) & $0.40 \pm 0.01$ & $0.40 \pm 0.01$ & ÖD \\
\hline 2. Ölçüm (53. Hafta) & $0.39 \pm 0.01$ & $0.39 \pm 0.01$ & ÖD \\
\hline 3. Ölçüm (55. Hafta) & $0.39 \pm 0.01$ & $0.39 \pm 0.01$ & ÖD \\
\hline 4. Ölçüm (59. Hafta) & $0.38 \pm 0.01$ & $0.40 \pm 0.01$ & (P<0.001) \\
\hline Kırık Yumurta Oranı (\%) & $2.11 \pm 0.05$ & $1.95 \pm 0.04$ & (P<0.05) \\
\hline
\end{tabular}

ÖD: Önemli değil.

Tablo 3. Bitkisel (Solanum glaucophyllum) kaynaklı 1.25(OH) $)_{2} \mathrm{D}_{3}{ }^{\prime}$ ün kuluçka sonuçlarına etkisi.

Table 3. Effect of herbal (Solanum glaucophyllum) $1.25(\mathrm{OH})_{2} \mathrm{D}_{3}$ on hatching results.

\begin{tabular}{|l|c|c|c|}
\hline \multirow{2}{*}{} & \multicolumn{2}{|c|}{ GRUPLAR } & \multirow{2}{*}{} \\
\cline { 2 - 3 } & $\begin{array}{c}\text { Kontrol } \\
\bar{X} \pm \mathrm{S} \bar{X}\end{array}$ & $\begin{array}{c}\text { Deneme } \\
\bar{X} \pm \mathrm{S} \bar{X}\end{array}$ & \\
\hline Dölsüz Yumurta Oranı (\%) & $7.79 \pm 0.29$ & $7.71 \pm 0.27$ & ÖD \\
\hline Çıkım Oranı (\%) & $82.71 \pm 0.09$ & $82.64 \pm 0.10$ & ÖD \\
\hline Iskarta Civciv Oranı (\%) & $1.41 \pm 0.07$ & $1.46 \pm 0.06$ & ÖD \\
\hline Embriyo Ölümü Oranı (\%) \\
\hline Erken Dönem & $2.96 \pm 0.10$ & $2.88 \pm 0.08$ & ÖD \\
\hline Orta Dönem & $0.56 \pm 0.05$ & $0.60 \pm 0.05$ & ÖD \\
\hline Geç Dönem & $4.56 \pm 0.19$ & $4.71 \pm 0.20$ & ÖD \\
\hline
\end{tabular}

ÖD: Önemli değil.

\section{Tartışma ve Sonuç}

$\mathrm{Bu}$ araştırma, damızlık broylerler 49 haftalık yaşta iken başlatılmış ve araştırmaya 10 hafta süreyle devam edilmiştir. Araştırma süresince yapılan ölçümlerde $(51,53,55$ ve 59 . haftalar) kontrol ve deneme grubunun yumurta ağıllıkları arasında oluşan farklılıklar istatistik açıdan önemli bulunmamıştır. Benzer şekilde hayvanlar 51, 53 ve 55 haftalık yaşta iken grupların yumurta kabuk kalitesine ilişkin parametrelerinde de önemli bir farklılık saptanmamıştır. Ancak damızlık broyler rasyonlarına katılan Solanum glaucophyllum kaynakl $1.25(\mathrm{OH})_{2} \mathrm{D}_{3}$; hayvanlar 59 haftalık yașta iken yumurta kabuk kalınlığı $\quad(\mathrm{P}<0.001)$, kabuk kırılma direnci $(\mathrm{P}<0.05)$ ve kırık yumurta oranında $(\mathrm{P}<0.05)$ istatistik düzeyde bir iyileşmeye yol açmıştır (Tablo 2). Damızlık broyler rasyonlarına katılan $1.25(\mathrm{OH})_{2} \mathrm{D}_{3}$ 'ün; 51,53 ve 55 . haftalarda yumurta kabuk kalitesi üzerinde her hangi bir etkisi saptanmazken, 59. haftada yumurta kabuk kalitesinde istatistik düzeyde iyileşmeye yol açması hayvanların yaşına bağlanmıştır. Elaroussi ve ark. ${ }^{9}$ vitamin $\mathrm{D}_{3}$ 'ün kanatlı vücudunda biyolojik olarak aktif olan $1.25(\mathrm{OH})_{2} \mathrm{D}_{3}$ formuna dönüștüğü hidroksilasyon basamaklarında yaşın ilerlemesiyle birlikte aksaklıkların yaşandığını öne sürmüşlerdir. Nitekim Bar ve Hurwitz $^{4}$ kanatlı hayvanlarda yumurtlama devresinin başlangıcında oldukça yüksek olan yumurta kabuk kalitesinin, yumurtlama devresinin ileriki aşamalarında $\mathrm{Ca}$ ve vitamin $\mathrm{D}_{3}$ metabolizmasındaki aksaklıklardan dolay1 giderek azaldığını ve bu durumun ince kabuklu yumurtaların oranında artışa yol açtığını bildirmişlerdir. Bu araștırmada hayvanlar 59 haftalık yaşta iken deneme grubunun yumurta kabuk kalınlığ ve kabuk kırılma direncinde saptanan önemli düzeydeki artıș, kırık yumurta oranının istatistik düzeyde azalmasıyla sonuçlanmıștır. Kabuk kalitesinde gözlenen bu iyileşmenin rasyona katılan Solanum glaucophyllum kaynakl1 $1.25(\mathrm{OH})_{2} \mathrm{D}_{3}$ 'ün $\mathrm{Ca}$ metabolizmas1 üzerindeki pozitif etkisinden kaynaklanabileceği düşünülmektedir. Nitekim Solanum glaucophyllum'un $1.25(\mathrm{OH})_{2} \mathrm{D}_{3}$ 'ün doğal kaynağı olduğunu ortaya koymak amacıyla yapılan ilk çalışmalarda ${ }^{15,17}$, bitkinin yapraklarından elde edilen ekstraktların vitamin $\mathrm{D}$ bakımından yetersiz beslenen civciv ve ratlarda $\mathrm{Ca}$ absorbsiyonunu önemli düzeyde $\operatorname{artırdığ} 1$ tespit edilmiştir. Cheng ve ark. ${ }^{6}$ tarafindan broylerler üzerinde yapılan diğer bir çalıșmada; Solanum glaucophyllum'un yaprakları 5 ppm dozda rasyona katılmış, araştırmanın 
sonunda plazma Ca ve fosfor konsantrasyonu ile kemik külü ve kemik yoğunluğunda istatistik düzeyde bir artış saptanmıştır. Vitamin $\mathrm{D}_{3}$ 'ün biyolojik olarak aktif formu olan $1.25(\mathrm{OH})_{2} \mathrm{D}_{3}$ 'ün, bağırsak epitelyumunda $\mathrm{Ca}$ bağlayıcı proteinlerin sentezini uyarmak suretiyle Ca absorbsiyonunu artırdığ bildirilmiştir ${ }^{4}$. Barsak epitelyumunda saptanan $\mathrm{Ca}$ bağlayıcı proteinlere aynı zamanda yumurta tavuklarının uterusunda da rastlanmıştır ${ }^{10}$. Bu proteinlerin Ca'un yumurta kabuğuna transfer olmasını sağlayarak yumurta kabuğunun şekillenmesinde önemli bir rol oynadıkları öne sürülmüştür ${ }^{3}$.

$\mathrm{Bu}$ araştırmada; kontrol ve deneme grubunun kuluçka sonuçlarına ilişkin dölsüz yumurta, çıkım, 1skarta civciv, erken, orta ve gec dönem embriyo ölüm oranları arasında önemli bir farklılık saptanmamıştır (Tablo 3). Bilindiği gibi damızlık olarak yetiștirilen kanatlı hayvanlarda kuluçka sonuçlarına direkt etkisinden dolayı üretilen kuluçkalık yumurtaların yüksek kabuk kalitesine sahip olması istenmektedir. Hunton ${ }^{11}$ kuluçkalık yumurtalarda yumurta kabuğunun; embriyoyu dış etkilerden ve enfeksiyonlardan koruyarak, yumurtadan su kayıplarını önleyerek, ayrıca iskelet gelişimi için embriyoya gerekli Ca'u sağlayarak önemli bir görev üstlendiğini bildirmiștir. Ancak bu araştırmada hayvanlar 59. haftalık yașta iken deneme grubunun yumurta kabuk kalitesinde saptanan iyileşme, kuluçka sonuçlarına yansımamıştır. Araștırma süresince 59. haftaya kadar periyodik olarak yapılan ölçümlerde yumurta kabuk kalitesi bakımından gruplar arasında önemli bir farklığın saptanmaması; 59. haftada yumurta kabuk kalitesinin bozulmaya başladığını ve böylece rasyona katılan $1.25(\mathrm{OH})_{2} \mathrm{D}_{3}$ 'ün etkisinin açığa çıktığını düşündürmektedir. Bu dönemin araştırmanın sonlandırıldığı haftaya rastlamasından dolay1, deneme grubunun yumurta kabuk kalitesinde gerçekleşen iyileşmenin kuluçka sonuçlarına yansımadığı kanısına varılmıştır.

$\mathrm{Bu}$ araştırmadan elde edilen veriler değerlendirildiğinde; Solanum glaucophyllum kaynakl1 $1.25(\mathrm{OH})_{2} \mathrm{D}_{3}$ 'ün; Ca ve vitamin $\mathrm{D}_{3}$ metabolizmasının aksadığ ileri yaş dönemindeki damızlık broyler rasyonlarına katılması durumunda yumurta kabuk kalitesini iyileştirebileceği sonucuna varılmıștır. Kuluçka sonuçları üzerindeki etkisinin ise damızlık broylerler üzerinde gerçekleştirilecek daha uzun süreli denemelerle ortaya konulabileceği düşünülmektedir.

\section{Kaynaklar}

1. Araujo-Torres, C., Luiz-Vieira, S., NuernbergReis, R., Klein-Ferreira, A., Xavier da Silva, P., Foch- Furtado, F.V., 2009. Productive performance of broiler breeder hens fed 25 hydroxycholecalciferol. Rev. Bras. Zootec., 38, 12861290.

2. Balnave, D., Muheereza, S.K., 1997. Improving eggshell quality at high temperatures with dietary sodium bicarbonate. Poult. Sci., 76, 588-593.

3. Bar, A., Hurwitz, S., 1973. Uterine calcium binding protein in the laying fowl. Comp. Biochem. Physiol., 45, 579-586.

4. Bar, A., Hurwitz, S., 1987. Vitamin D metabolism and calbindin (calcium binding protein) in aged laying hens. J. Nutr., 117, 1775-1779.

5. Boland, R. L., Skliar, M. I., Norman, A. W., 1987. Isolation of vitamin $\mathrm{D}_{3}$ metabolites from Solanum malacoxylon leaf extracts incubated with ruminal fluid. Planta Med., 53, 161-164.

6. Cheng, Y.H., Goff, J.P., Sell, J.L., Dallorsa, M.E., Gil, S., Pawlak, S.E., Horst, R.L., 2004. Utilizing Solanum glaucophyllum alone or with phytase to improve phosphorus utilization in broilers. Poult., Sci., 83, 406-413.

7. Combs, G. F. Jr., 1998. Vitamin D. The Vitamins: Fundamental Aspects in Nutrition and Health. $2^{\text {nd }}$ Ed., San Diego, California, pp. 156-186.

8. DeLuca H.F., 1988. The vitamin D story: A collaborative of basic science and clinical medicine. Faseb J., 2, 224-236.

9. Elaroussi, M. A., L. R. Forte, S. L. Eber, H. V. Biellier., 1994. Calcium homeostasis in the laying hen 1 . Age and dietary calcium effects. Poult. Sci., 73, 1581-1589.

10. Fuller, C. S., Brindak, M. E., Bar, A., Wasserman, R. H., 1976. The purification of calcium binding protein from the uterus of the laying hen. Proc. Soc. Exp. Biol. Med., 152, 237-241.

11. Hunton, P., 2005. Research on eggshell structure and quality: An historical overview. Braz. J. Poult. Sci., 2, 67-71.

12. Narbaitz, R., Tsang, C. P. W., 1989. Vitamin D deficiency in the chick embryo: The effects of prehatching motility and on the growth and differentiation of bones, muscles and parathyroid glands. Calcif. Tiss. Int., 44, 348-55.

13. Narbaitz, R., Tsang, C. P. W., Grunder, A., 1987. The effects of vitamin $\mathrm{D}$ deficiency in the chick embryo. Calcif. Tiss. Int., 40, 109-113.

14. Norman, A.W., Roth, J., Orci, L., 1982. The vitamin D endocrine system: steroid metabolism, hormone receptors, and biological response (calcium binding proteins). Endoc. Rev., 3, 331-366. 
15. Schneider, L.E., Schedl, H.P., 1977. Effects of Solanum malacoxylon on duodenal calcium binding protein in the diabetic rat. Endocrinology, 100, 928-933.

16. SPSS. 1999. SPSS for Windows, SPSS 13. 2004. SPSS INC.. Chicago. IL. USA.

17. Wasserman, R.H., Henion, J.D., Haussler, M.R., McCain, T.A., 1976. Calcinogenic factor in Sola- num malacoxylon: Evidence that it is 1.25dihydroxyvitamin $\mathrm{D}_{3}$-glycoside. Science, 194, 853-855.

18. Wilson, H. R., 1997. Effects of maternal nutrition on hatchability. Poult. Sci., 76, 134-143. 